DOI: 10.12731/wsd-2018-5-132-143

UDC 579.841.11

\title{
OPPORTUNISTIC BACTERIA: PSEUDOMONAS PUTIDA
}

\section{Haffaressas Y., Ayad N., Boussayoud R., Mouffok F.}

Background. This work aims to identify bacterial strains of Pseudomonas putida; opportunistic bacteria in groundwater in Algeria and to try to explain why their numbers are increasing this year compared to the previous year.

Materials and Methods. 46 groundwater samples were taken during the period from july 2016/ march 2017 at the level of 18 cities and 210 groundwater samples were taken during the period of january 2017 / october 2018 (32 cities in Algeria). Water was analyzed by the membrane filtration technique. After incubation, the characteristic colonies are identified by biochemical tests and $20 \mathrm{NE}$ biochemical gallery.

Results and Discussion. We saw an increase number of Pseudomonas putida in the last and current year, the value is almost $1100 \mathrm{ufc} / 250 \mathrm{ml}$. An increase that can be explained by an optimal temperature between $25^{\circ} \mathrm{C}$ and $30^{\circ} \mathrm{C}$ and an optimal $\mathrm{pH}$ which is between 4 to 8 . The use of P. putida strains in industrial processes, commercial products or consumer products may explain the high number of these bacterial strains in groundwater in Algeria.

Conclusion. Pseudomonas putida strains appear to be closely related to Pseudomonas fluorescens and that molecular biology techniques must be used to properly identify these two types of bacteria and to construct a phylogenetic tree of strains. Pseudomonas putida strains have no negative effect on the environment or on biological diversity; or endanger the environment that is essential to life and human health. Exposed the strains of P.putida bacteria for a long time to biocides and antibiotics may constitute a battery of defense mechanisms regardless of their targets of action.

Keywords: Pseudomonas putida; Pseudomonas fluorescens; Pathogen; Environment; Groundwater.

\section{INTRODUCTION}

Pseudomonas putida is a rod-shaped, flagellated, gram-negative bacterium that is found in most soil and water habitats where there is oxygen. It grows optimally at $25-30^{\circ} \mathrm{C}$ and can be easily isolated. Pseudomonas putida has several strains including the KT2440, a strain that colonizes the plant roots in 
which there is a mutual relationship between the plant and bacteria. The surface of the root, rhizosphere, allows the bacteria to thrive from the root nutrients. In turn, the Pseudomonas putida induces plant growth and protects the plants from pathogens. Because Pseudomonas putida assist in promoting plant development, researchers use it in bioengineering research to develop biopesticides and to the improve plant health [1]. Pseudomonas putida has a very diverse aerobic metabolism that is able to degrade organic solvents such as toluene and also to convert styrene oil to biodegradable plastic Polyhydroxyalkanoates (PHA). This helps degrade the polystyrene foam which was thought to be non-biodegradable. Due to the bacteria's strong appetite for organic pollutants, researchers are attracted to using Pseudomonas putida as the "laboratory 'workhorse' for research on bacteria-remediated soil processes" [2]. This bacteria is unique because it has the most genes involved in breaking down aromatic or aliphatic hydrocarbons which are hazardous chemicals caused by burning fuel, coal, tobacco, and other organic matter. There is great interest in sequencing the genome of Pseudomonas putida due to its strong effect in bioremediation [3]. Through the genome analysis, Pseudomonas putida is found to have approximately 6.2 million DNA base pairs. Among the Pseudomonas putida, the strain F1 is 5,959,964 nucleotides long and contains $61 \%$ guanine and cytosine content and $39 \%$ adenine and thymine content. While another important strain, KT2440 is 6,181,863 nucleotides long [4]. Pseudomonas putida has a circular genome where at least eighty genes in oxidative reductases, a family of enzymes, are involved in decomposing substances in the environment.

The objective of this work is to identify an opportunistic bacterium Pseudomonas putida in groundwater in Algeria and why their number has increased this year compared to the previous year.

\section{Ecology}

Pseudomonas putida are significant to the environment due to its complex metabolism and ability to control pollution. There is a high versatility of bacterial communities towards contaminations which is further increased by certain catabolic sequences on the TOL plasmids in the cell [5]. Even the plasmids are important in sensing the environmental stress. Some of the environmental stresses are caused by benzene, xylene, and toluene, the main components of gasoline and are major sources of water contamination. Pseudomonas putida can degrade the hydrocarbons of these organic solvents through oxidative reactions therefore placing Pseudomonas putida as one of the most important microbes in bioremediation [6]. 
Pseudomonas putida also interacts with other organisms in the soil. One such interaction with Saccharomyces cerevisiae in the rhizosphere led to beneficial effects on the state of the Pseudomonas putida. Fungi Saccharomyces cerevisiae produced the necessary glucose and also maintained the $\mathrm{pH}$ which was both favorable to the bacteria Pseudomonas putida [7]. The complex interaction of Pseudomonas putida and Saccaromyces cerevisiae together regulate plant health. Moreover, the bacteria itself is a great maintainer of abundant plant life. The production of the siderophores, such as pyoverdine and pyochelin, protect the plants from fungal pathogens. The mutual relationship benefits both partners. While Pseudomonas putida is able to reside in the plant seed and rhizosphere, the plant is, in turn, protected from plant pathogens and able to obtain vital nutrients from the bacteria [8].

\section{Metabolic pathways of Pseudomonas putida}

Pseudomonas putida has metabolism functions in biodegradable plastics. Styrene degradation in Pseudomonas putida CA-3 degrades styrene in two pathways : vinyl side chain oxidation and attack on the aromatic nucleus of the molecule[9] Pseudomonas putida also has sideospores, an iron chelating compound that allows the bacteria to enhance levels of iron and promote the active transport chain [10]. Strains of Pseudomonas putida have outer membrane receptor proteins that help transport the iron complex to the sideospores, specifically known as pyoverdines, which are found in the bacterial cell. From there the iron is used in metabolic processes where oxygen is the electron acceptor [11]. Oxygen serves as a good electron acceptor. The oxygen byproducts, however, are toxic to the bacteria including superoxide and hydrogen peroxide. In response, Pseudomonas putida produces catalase to protect the cell from the reactive properties of the byproducts [12]. In addition, Pseudomonas puti$d a$ has important lipids that are developed as an adaptation mechanism to respond to physical and chemical stresses. The bacteria is able to change its degree of fatty acid saturation, the cyclopropane fatty acids formation, and the cis-trans isomerization. In different phases, the cell changes its characteristics to better respond to the environment. During the transition from growth to stationary phase, there is a higher degree of saturation of fatty acid and a higher membrane fluidity which improves substrate uptake, thus regulating the cell [13]. All these characteristics allow Pseudomonas putida to survive deadly toxins in the soil and allow it to thrive in contaminated areas. Its metabolism allows these bacteria to convert harmful organic solvents to nontoxic composites which are so essential to bioremediation. In addition to the abili- 
ty for $P$. putida to degrade synthetic compounds, it can also use an alternative metabolic pathway such as the Entner-Doudoroff pathway. In this pathway, P. putida degrades common hexoses, such as glucose and gluconate (figure 1), to yield one net ATP for every glucose molecule degraded. This is in contrast to the two net ATP produced for every glucose molecule degraded in the classic glycolysis pathway. The Entner-Doudoroff pathway begins by converting glucose to gluconate-6-phosphate through two intermediates. The first intermediate is gluconate which is then converted to 2-ketogluconate. 2-ketogluconate is then converted to gluconate-6-phosphate. It should be noted that in some cases, gluconate-6-phosphate can be produced directly via phosphorylation of gluconate. The gluconate-6-phosphate is converted to 2-Keto-3-deoxy-gluconate-6-phosphate (KDGP). Finally, KDGP is converted to triosephosphate and pyruvate. Interestingly, $P$. putida has many alternative pathways that it can utilize to produce energy, yet it does not use them and mainly relies on the Entner-Doudoroff pathway outlined above [14].



\section{Pathology}

In genetic terms, Pseudomonas putida is very similar to strains of Pseudomonas aeruginosa, an opportunistic human pathogen. Although there is a considerable amount of genome conservation, $P$. putida seems to be missing the key virulent segments that $P$. aeroginosa has. Being a non-pathogenic bacteria, there has been only a handful of episodes where $P$. putida has infected humans. For the most part, it has been with immunocompromised patients, 
causing septicaemia, pneumonia, urinary tract infections, nosocomial bacteremia, septic arthritis, or peritonitis. P. putida is also closely related to Pseudomonas syringae, an abundant plant pathogen, but again it lacks the gene that causes such disease. Several cases of disease caused by Pseudomonas puti$d a$ have been investigated, being that the bacterium rarely colonizes mucosal surfaces or skin. One case was a 43-year-old female who was receiving nightly peritoneal dialysis treatments following a laparoscopic ovarian cyst operation. She developed peritonitis due to infection by Pseudomonas putida. Through this case and others, it was determined that risk factors for developing such an infection include the insertion of catheters, intubation, and/or intravascular devices following a recent course in antibiotics [15].

Another case of Pseudomonas putida infection was found in ten patients in and ear, nose, and throat outpatient clinic during the summer of 2000. All ten patients had chronic sinusitis, making them more susceptible to infection due to their challenged immune systems. Through investigation, it was discovered that all of the patients shared the same examination room. The source of the bacteria was from a contaminated bottle of StaKleer found in that room. StaKleer is an anti-fog solution used on mirrors and endoscopes to prevent condensation from occurring, allowing for the proper visualization of tissues. Other unopened bottles of the solution at the clinic were found to be contaminated with Pseudomonas putida as well [16].

\section{Biocide and antimicrobial resistance}

Biocides and antibiotics have similarities in terms of bacterial resistance despite differences in their mode of action. Overall, exposed bacteria (including P.putida) to these two categories of antimicrobial products can set up a battery of defense mechanisms independently of their action targets [17].These defense mechanisms are: either innate, stable and most commonly present in all strains of a genus or bacterial species (resistance is called intrinsic or natural); They are transferable to offspring because they are carried by the chromosome (vertical transmission) and can confer high resistance to antimicrobial products (biocides and antibiotics); Or acquired by various mechanisms (the resistance is called acquired) such as chromosomal mutations or acquisition of mobile extra-chromosomal DNA; They are transferable from one bacterium to another and / or to the offspring. The first line of defense against attacks of external chemicals is the stimulation of bacterial regulators triggering a barrier effect of the membrane. Two mechanisms are described in order to control the intracellular antimicrobial concentration: the decrease of the influx, reducing 
the expression of active porins present at the level of the external membrane or modifying the structure of lipo-polysaccharides, proteins or lipids [18], constituting the bacterial wall [19]. Expression or overexpression of efflux pumps expelling toxic substances from bacteria. This last mechanism is most often described. These efflux pumps can be specific to one or more chemical substances (antimicrobial products, dyes, metals) such as MDR pumps for Multi Drug Resistance pumps [20]. It seems that several defense mechanisms can most often be used by a bacterium to defend against chemical stress that can be represented by the biocide [21]. Other mechanisms may include spontaneous mutations at the DNA level and the acquisition of mobile genetic elements (plasmids, transposons). These mobile genetic elements code for membrane transporters that will carry a single molecule or, more often, different molecules of varied chemical structure. They are transferred from one bacterium to another by one of the following three mechanisms: conjugation (conjugative plasmids), transformation (bare DNA) and transduction (phages). These horizontal transfers are generally more frequent than the mutation phenomena. More rarely, these genetic elements can also code for resistance factors such as enzymes that will alter or inactivate the biocide. With the exception of mutations, other mechanisms (efflux, permeability modification, enzymatic modification) may be involved in both natural and / or acquired resistance. Exposure to biocides may also lead to adaptations of bacteria to environmental changes resulting in changes in their phenotype allowing them to survive (changes in growth rate, small colonies, decreased invasiveness). This state of physiological adaptation is transient and disappears in the absence of contact with the biocide. The few mechanisms that play an important role in resistance are controlled by cascaded gene controls that share common regulators (SoxS, MarA) [22].

\section{Resistance to antibiotics}

Antibiotics used in humans and animals have been used to treat P. putida infections, including aminoglycosides, carbapenemes, fluoroquinolones, piperacillin, ceftazidime, levofloxacin and ciprofloxacin [23]. However, resistance to carbapenems, cephalothin, ampicillin, chloramphenicol and carbenicillin has been observed in some isolates of P. putida. Environmental isolates have been shown to be resistant to penicillin, ampicillin, oxacillin, cephalothin, erythromycin, vancomycin and trimethoprim. Multidrug-resistant $P$. putida isolates have been found in the urine of intensive care patients with nosocomial infections [24]. These isolates contained conjugative and non-conjugative $\mathrm{R}$ plasmids encoding IMP and VIM-type metallo- $\beta$-lactamases which confer resistance 
to high concentrations of carbapenems and other $\beta$-lactamines. In addition, new class 1 integrons, encoding multiresistance, were isolated from 12 strains of $P$. putida in southern China [25]. Clinical strains of P. putida may be a nosocomial reservoir of transferable resistance determinants. The TriRY strain of $P$. putida is resistant to triclosan antimicrobial and can use this substance as a carbon source. Health Canada scientists have verified the resistance of $P$. putida strains to antibiotics of different classes. Sensitivity profiles are similar to those reported in the literature for resistant strains. Overall, the most effective antibiotic is ciprofloxacin, while amoxicillin, amphotericin B, cefotaxime, erythromycin, nalidixic acid, trimethoria and vancomycin are inactive against all isolated strains [26].

\section{The choice of antibiotic treatment for P.putida}

Strains of Pseudomonas putida that produce metallo-beta-lactamases (MBLs) are difficult to treat because effective antibiotics are lacking. Colistin, the traditional drug of last resort and the choice of antibiotic treatment for $P$. putida infections is thus limited. Combination therapy including arbekacin (ABK), an aminoglycoside antibiotic, has been reported to be effective against multidrug-resistant Pseudomonas aeruginosa in vitro [27]. Arbekacin is a broad-spectrum aminoglycoside antibiotic, effective in treating infections with a range of bacteria, from Gram-positive cocci to Gram-negative bacilli. This antibiotic is indicated for treatment of infections with methicillin-resistant $S$. aureus and has been reported to effectively kill Pseudomonas spp. $\mathrm{ABK}$ is a relatively new drug, and the pharmacokinetics and pharmacodynamics there of remain not to be fully investigated. The optimal blood concentration of ABK has not yet been established. For aminoglycoside drugs, the ratio of peak blood concentration $\left(C_{\text {peak }}\right)$ to the minimal inhibitory concentration has been reported to be related to the clinical efficacy. Thus, a $C_{\text {peak }} / \mathrm{MIC}$ value greater than 8 was associated with a clinical efficacy of over $90 \%$ [28].

\section{MATERIALS AND METHODS}

46 groundwater samples were taken during the period from july 2016/ march 2017 at the level of 18 cities and 210 groundwater samples were taken during the period of january 2017 / october 2018 (32 cities in Algeria).Water was analyzed by the membrane filtration technique [29]. After incubation, the characteristic colonies are identified by biochemical tests based essentially on oxidase, orthonitrophenyl- $\beta$-galactoside, tri sugar iron: $15 \mathrm{~g}$ casein peptones, $5 \mathrm{~g}$ meat peptones, $3 \mathrm{~g}$ meat extracts, $3 \mathrm{~g}$ yeast peptides, $5 \mathrm{~g} \mathrm{NaCl}, 10 \mathrm{~g}$ Lactose, $10 \mathrm{~g}$ sucrose, $1 \mathrm{~g}$ glucose, $0,5 \mathrm{~g}$ ammoniacal citrate of iron (III), 0,5 $\mathrm{g}$ sodium 
thiosulphate, 0,024 $\mathrm{g}$ phenol red, $12 \mathrm{~g}$ agar. Urea-Indole, lysine decarboxylase, and identification by a $20 \mathrm{NE}$ biochemical gallery containing 20 microtubes containing dehydrated substrates inoculated with a bacterial saline suspension, the reactions produced during the incubation period result in spontaneous colored turns or revealed by the addition of reagents [30].

\section{RESULTS AND DISCUSSION}

\section{Microbiological quality of groundwater}

The assessment of the bacteriological quality of the waters in the area was followed by the analysis of the water harvested at 18 and 32 cities during the period of July 2016/ March 2017 and January 2017 / October 2018.

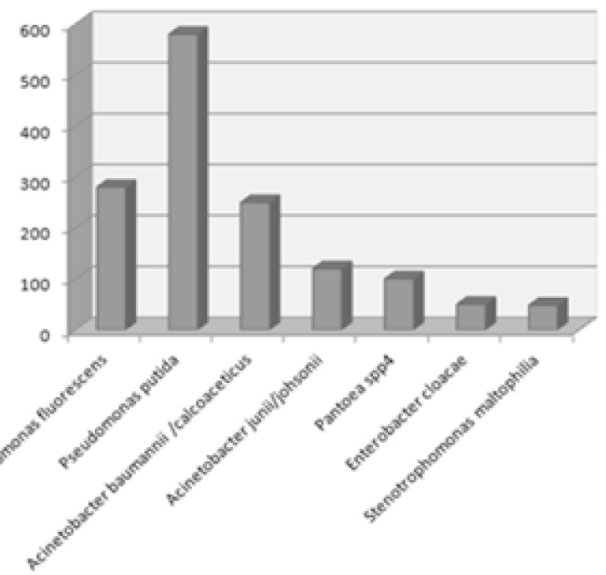

" Number of Bacteria ufe $250 \mathrm{ml}$

Fig.2 Pseudomonas putida and other bacteria found in groundwater in Algeria (2016/2017)

During the study period 2016/2017, the maximum value of Pseudomonas putida and Pseudomonas oryzihabitans, Pseudomonas stutzeri are close to $600 \mathrm{ufc} / 250 \mathrm{ml}$, while for the other bacteria: Pseudomonas fluorescens, Pseudomonas alcaligenes,Pseudomonas luteola Acinetobacter baumannii / calcoaceticus, Acinetobacter junii / johsonii, Pantoea spp 4 Enterobacter cloacae,Stenotrophomonas maltophilia their max values are respectively of the order of: $300,0,25,280,250,120,100,50,48 \mathrm{ufc} / 250 \mathrm{ml}$. We saw an increase number of Pseudomonas putida in the last and current year, the value is almost $1100 \mathrm{ufc} / 250 \mathrm{ml}$. An increase that can be explained by an optimal temperature between $25^{\circ} \mathrm{C}$ and $30^{\circ} \mathrm{C}$ and an optimal $\mathrm{pH}$ which is between 4 to 8 . 


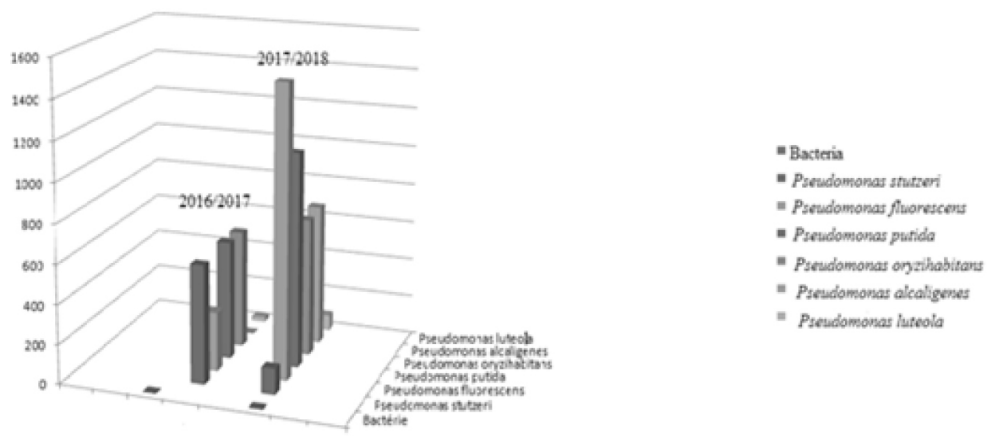

Fig.3 Pseudomonas putida and other species of Pseudomonas found in groundwater in Algeria

\section{CONCLUSION}

$P$. putida strains are not closely related to pathogenic microorganisms such as $P$. aeruginosa and that comparison of environmental data for $P$. putida strains allowed P. putida strains to be matched to P. putida and P. fluorescens: P. putida strains appear to be closely related to $P$. fluorescens and that molecular biology techniques must be used to properly identify these two types of bacteria and to construct a phylogenetic tree of strains.

P. putida strains have no negative effect on the environment or on biological diversity; or endanger the environment that is essential to life and human health. Exposed the strains of P.putida bacteria for a long time to biocides and antibiotics may constitute a battery of defense mechanisms regardless of their targets of action. The use of $P$. putida strains in industrial processes, commercial products or consumer products may explain the high number of these bacterial strains.

\section{References}

1. Espinosa-Urgel M., Salido A., Ramos J. "Genetic Analysis of Functions Involved in Adhesion of Pseudomonas putida to Seeds". Journal of Bacteriology. May 2000. Volume 182, pp. 2363-2369.

2. Kowalski H. "U.S. - German Research Consortium Sequences Genome of Versatile Soil Microbe". J.Craig Venter Archive. December 2002.

3. Marcus A. "Versatile soil-dwelling microbe is mapped". Genome News Network. January 2003.

4. NCBI. http://www.ncbi.nlm.nih.gov/sites/entrez?Db=genome\&Cmd=ShowDetailView\&TermToSearch $=21068$ 
5. Reanney D., Gowland P., Slater J. "Genetic Interactions Among Communities". Microbes in Their Natural Environments. April 1983. Volume 34. P. 408.

6. Otenio M.H., Lopes da Silva M.T., Marques M., Roseiro J., Bidoia E. "Benzene, Toluene and Xylene Biodegradation by Pseudomonas putida CCMI 852”. Brazilian Journal of Microbiology. Volume 36, pp. 258-261. http://www. scielo.br/pdf/bjm/v36n3/arq10.pdf

7. Romano J., Kolter R. "Pseudomonas-Saccharomyces Interactions: Influence of Fungal Metabolism on Bacterial Physiology and Survival". Journal of Bacteriology. February 2005. Volume 187. p.940-948. http://jb.asm.org/cgi/content/ full/187/3/940

8. Espinosa-Urgel M., Salido A., Ramos J. “Genetic Analysis of Functions Involved in Adhesion of Pseudomonas putida to Seeds". Journal of Bacteriology. May 2000. Volume 182, pp. 2363-2369. http://jb.asm.org/cgi/content/full/182/9/2363

9. O'Connor K., Duetz W., Wind B., Dobson A.D.W. "The Effect of Nutrient Limitation of Styrene Metabolism in Pseudomonas putida CA-3". Applied and Environmental Microbiology. October 1996. Volume 62, pp. 3594-3599.

10. Boopathi E., Rao K.S. "A sideophore from Pseudomonas putida type A1: structural and biological characterization”. November 1999. Volume 1435, pp. 30-40.

11. Lopez J.E., Henkels M.D. "Utilization of Heterologous Siderophores Enhances Levels of Iron Available to Pseudomonas putida in the Rhizosphere". Applied and Environmental Microbiology. December 1999. Volume 65, pp. 5357-5363.

12. Miller C.D., Kim Y.C., Anderson A.J. "Cloning and mutational analysis of the gene for the stationary-phase inducible catalase (catC) from Pseudomonas putida". Journal of Bacteriology. August 1997. Volume 179, pp. 5241-5245.

13. Härtig C., Loffhagen N., Harms H. "Formation of trans Fatty Acids Is Not Involved in Growth-Linked Membrane Adaptation of Pseudomonas putida". Applied and Enbironmental Microbiology. April 2005. Volume 71, pp. 1915-1922.

14. M. Vicente and J.L. Canovas. "Glucolysis in Pseudomonas putida: Physiological Role of Alternative Routes from the Analysis of Defective Mutants" Journal of Bacteriology, 1973. Volume 116, pp. 908-914.

15. Dervisoglue E., Dundar D.O., Yegenaga I., Willke A. "Peritonitis due to Pseudomonas putida in a Patient Receiving Automated Peritoneal Dialysis". Infection. 2007.

16. Otenio M.H., Da Silva M.T.L., Marques M.L.O, Roseiro J.C., Bidoia E.D. "Benzene, Toluene, and Xylene Biodegradation by Pseudomonas putida CCMI 852". Brazilian Journal of Microbiology. 2005, pp. 258-261.

17. Russell A.D. 2002. Antibiotic and biocide resistance in bacteria: introduction. Journal of applied microbiology, 1S-3S: 92. 
18. Guerin-Mechin L., Dubois-Brissonnet F., Heyd B. et Leveau J.Y., 1999. Specific variations of fatty acid composition of Pseudomonas aeruginosa ATCC 15442 induced by quaternary ammonium compounds and relation to bactericidal activity Journal of applied microbiology 87: 735-742.

19. Tattawasart U., Maillard J.Y., Furr J.R. et Russell A.D., 1999. Development of resistance to chlorhexidine diacetate and cetylpyridinium chloride in Pseudomonas stutzeri and changes in antibiotic susceptibility. Journal of Hospital Infection, 42: 219-29.

20. Hansen L.H., Jensen L.B., Sorensen H.I. et Sorensen S.J., 2007. Substrate specificity of the OqxAB multidrug resistance pump in Escherichia coli and selected enteric bacteria. J Antimicrob Chemother, 60: 145-7.

21. Bailey A.M., Constantinidou C., Ivens A., Garvey M.I., Webber M.A., Coldham N., Hobman J.L., Wain J., Woodward M.J. et Piddock L.J., 2009. Exposure of Escherichia coli and Salmonella enterica serovar Typhimurium to triclosan induces a species-specific response, including drug detoxification. Journal of Antimicrobial Chemotherapy, 64: 973-985.

22. Grkovic S., Brown M.H. et Skurray R.A., 2002. Regulation of bacterial drug export systems. Microbiology and Molecular Biology Reviews. 66: 671-701.

23. Chen G.Q., Wu Q., 2005. The application of polyhydroxyalkanoates as tissue engineering materials. Biomaterials 26, 6565-6578.

24. Lombardi G., Luzzaro F., Docquier J.D., Riccio M.L., Perilli M., Colì A., Amicosante G., Rossolini G.M., Toniolo A. Nosocomial Infections Caused by Multidrug-Resistant Isolates of Pseudomonas Putida Producing VIM-1 Metallo- $\beta$-Lactamase. J Clin Microbiol 40 (11).2002, pp. 4051-4055.

25. Wu, H. Yue, J. Lu, C. Li.Characterization of rhizobacterial strain Rs-2 with ACC deaminase activity and its performance in promoting cotton growth under salinity stress world. J. Microbiol. Biotechnol., 28 (2012), pp. 2383-2393.

26. Environnement Canada. http://www.ec.gc.ca/ese-ees/F16CFAE3-F496-45509227-A130A74D2D03/FSAR-P-putida-FR.pdf

27. Araoka H., Baba M., Tateda K., Ishii Y., Oguri T., Okuzumi K., Oishi T., Mori S., Mitsuda T., Moriya K., Nakamori Y., Ohmagari N., Yamaguchi K., Yoneyama A. ABX Combination Therapy Study Group In vitro combination effects of aztreonam and aminoglycoside against multidrug-resistant Pseudomonas aeruginosa in Japan. Jpn J Infect Dis. 2012;65:84-87. [PubMed]

28. Moore R.D., Lietman P.S., Smith C.R. Clinical response to aminoglycoside therapy: importance of peak concentration to minimal inhibitory concentration. J Infect Dis. 1987; 155:93-99. doi: 10.1093/infdis/155.1.93. [PubMed]

29. Meyer A et al. Cours de microbiologie générale avec problèmes et exercices corrigés Broché//Doin France. 2004. P. 430. 
30. http://guillaumegaouyer.emonsite.com/medias/files/20130711200101098.pdf. Biomérieux, REF $2005007615 \mathrm{~J}$-FR 2006/02.Système d'identification des bacilles à gram négatif non entérobactéries et non fastidieux.

\section{DATA ABOUT THE AUTHORS}

Haffaressas Yacine, PhD Student in Microbiology

Pasteur Institute of Algeria yacinechabani@yandex.ru

Ayad Nassime, Doctor in Pharmacy

Pasteur Institute of Algeria

Boussayoud Rachida, Engineer in Biology

Pasteur Institute of Algeria

Mouffok Fawzia, Chief, Head of Laboratory Bacteriology of Water and Food, Environment

Pasteur Institute of Algeria 